\title{
Learning fire investigation the clean way: The virtual experience
}

\author{
Amanda Davies and Barney Dalgarno \\ Charles Sturt University \\ An Outstanding Paper Award recipient, ascilite Melbourne 2008 Conference
}

\begin{abstract}
The effective teaching of fire investigation skills presents logistical challenges because of the difficulty of providing students with access to suitable fire damaged buildings so that they can undertake authentic investigation tasks. At Charles Sturt University (CSU), in the subject JST415, Fire Investigation Cause and Origin Determination, the novel approach of providing students with a CD based virtual environment based on the scene of a burned down house, as an alternative to having them undertake investigation of a real fire scene, has been implemented. This paper describes a quantitative and qualitative study exploring the effectiveness of this teaching resource. A key finding from this study was that students felt that the virtual fire investigation task had important advantages over undertaking a real investigation task, even though there were some limitations in the overall degree of realism of the experience. The results also suggested that students found that the visual fidelity and navigation capabilities provided within the environment were quite adequate for carrying out their fire investigation activity. Importantly, students also felt that the ability to revisit the virtual scene as many times as they wanted, at a time convenient to them, gave it advantages over a real investigation task if they were to be provided with only one or the other.
\end{abstract}

\section{Introduction}

The increased demand globally for universities and training establishments to deliver learning experiences which will fulfil the needs and expectations of today's student is acknowledged as driving the search for and development of relevant, accessible, achievable higher education courses. An intrinsic component of Charles Sturt University Law Enforcement courses involves developing the students' understanding of investigation theory, skill and application. This focus on developing investigation skills, by its very nature, suggests a requirement to establish relationships with real time situations and events for students to apply their learning and test their newly acquired skills in preparation for their role in the real world. The delivery of investigation subjects has historically been complex and plagued by logistical issues and teaching fire investigation courses is no exception. One such area of investigation is the cause and origin of structural fires.

For fire investigation students Charles Sturt University has traditionally offered both a mixed mode delivery of learning through the combination of a residential short course of five days duration, with a component of distance education or a print based distance education course without a residential phase. The significance of this becomes apparent when traditionally, the inclusion in the residential phase of an investigation 
of a real time fire scene as an assessment element has been a pivotal concept. Here lies one of the problematic elements of teaching fire investigation, guaranteeing the availability of an uncontaminated fire scene for residential students to investigate, demonstrating the knowledge and skills acquired during the course of their study and providing the opportunity for aligned learning experiences which are time independent or asynchronous.

Since the inception of the residential short course phase, this logistic, availability of uncontaminated fire scenes has been managed through combining the timing of the delivery of the residential course with the training needs and cooperation of the New South Wales Rural Fire Service. A building is identified (within reasonable proximity of the residential course) in need of demolition, a permit sought for destruction by fire, NSW Rural Fire Volunteer training day programmed to coincide with igniting the building and extinguishing the resultant fire and a date released to students for attendance at the residential course. From 2005, in addition to the above, a further obstacle emerged in the form of new restrictions imposed by the NSW Protection of the Environment Operations Act 1997.

The development of the fire investigation course, JST415 Fire Investigation Cause and Origin Determination, which utilised previously filmed fire scenes converted into a virtual environment made up of navigable, photorealistic imagery for assessment of the students' investigation knowledge and skills, was the product of this challenge. The virtual environment uses Apple's QuickTime VR technology, which involves the 'stitching' together of a series of photographs making up one or more 360 degree panoramic images (Chen, 1995). The user then explores these images by panning, zooming or tilting the view direction upwards or downwards. By providing a mechanism for jumping from one view position to another, a photorealistic virtual environment can be created that is an alternative to virtual environments based on a 3D model. QuickTime VR environments have the advantage of greater visual fidelity than $3 \mathrm{D}$ virtual environments, but suffer from limitations in the navigation capabilities provided, because smooth movement between viewpoints is not possible.

A research project was undertaken which involved an evaluation of the resources developed for this course. The specific objectives of this project were to:

- firstly, identify any unique characteristics offered by the virtual environment in supporting the development of knowledge and skills for fire investigators;

- secondly, identify any perceived difference in the level of achievement of learning outcomes by fire investigation students when learning via face to face, distance education or a combination of these two methods; and

- thirdly, through analysing the learning experiences of the fire investigation students, identify the potential for reusable learning objects for the study of associated investigation subjects.

Four student cohorts who undertook the study of JST415 were included in the research. The four groups had discrete study pathways. Group 1 (to be referred to as the Short Course Real Time Fire Burn group or SCRTB) undertook a short residential face to face course and investigated a real time fire scene. This Group was provided with paper based reference materials for their studies. These reference materials were included in the JST415 CD. On completion of their studies, Group 1 was provided a copy of the JST415CD, with identical content and hyperlinks as the JST415 CD provided to Group 3 and Group 4 for evaluation. Group 2 (to be referred to as Short 
Course Virtual Assessment 1 or SCVA1) undertook a short residential face to face course and investigated version 1 of the virtual fire scene on a CD. Group 2 were provided with paper based reference materials as for Group 1 and the virtual fire scene CD contained only instructions for navigation of the scenes and the actual scenes. Group 3 (to be referred to as Short Course Virtual Assessment 2 or SCVA2) undertook a short residential face to face course and investigated version 2 of the virtual fire scene on the JST 415 CD and Group 4 (to be referred to as Distance Education Virtual Assessment 2 or DEVA2) undertook their study of the subject by distance education, with the learning material supplied on the JST415 CD and utilising version 2 of the virtual fire scene for assessment purposes.

This paper presents the findings in relation to the first research objective, namely, the identification of the unique characteristics offered by the virtual environment in supporting the development of knowledge and skills for investigators. Specifically this paper addresses the following research questions:

- Does the delivery of learning via the JST415 CD support the development of knowledge and skills for fire scene investigation?

- What are the main aspects of a VLE that contribute to the development of knowledge and skills for fire investigation students?

- What are the limitations of the use of a VLE when compared with a similar face to face experience and do these impact on learning?

\section{Concept of VLE}

The term virtual environment within the human computer interaction (HCI) community implies the use of a simulated environment, typically containing a 3D model allowing for user controlled navigation and dynamic view generation (see, for example Wann and Mon-Williams, 1996). Within the educational technology community, on the other hand, the term virtual learning environment (VLE) has increasingly become used to refer to web based learning resources which do not necessarily include any form of visual simulation (Dillenbourg, Schneider \& Synteta, 2002).

The term VLE was utilised for this project to reflect the variety of tools embraced by the JST415 CD, specifically, the inclusion of the photo realistic virtual environment created by the Interactive Scene Recording and Presentation (ISRAPS) software program which facilitated the recording and presentation of the real time fire scene onto the JST415 CD and to account for the participants' perceptions/labelling. The design and development of the JST415 CD was founded on constructivist learning principles and the relationship between virtual reality environments and the learning principles of situated cognition.

Constructivist learning principles embrace the concept that knowledge construction is learner managed, the construction of knowledge is influenced by previous experience, and influenced by the social and cultural context in which the learning is situated (see Jonassen, et. al. 2003; Jonassen, 1995). Here Jonassen further emphasises the importance of learners "actively interpreting and constructing individual knowledge representations" in the concept of constructivist learning principles. As suggested by Byrne (1996) whilst the actual methods of constructivist teachers may vary, the central 
concept remains that students should be fully involved in their education, not merely waiting to be told the correct answers. Bricken (1990) and Jonassen et. al. (2003) also suggest that the capabilities of virtual reality are compatible with constructivist learning principles.

Bell and Fogler (1996) in reporting on the use of virtual reality in an educational module for chemical reaction engineering, suggest that virtual reality has the potential to be a powerful new tool in engineering education, by providing experience based learning to a wider range of students with differing learning styles. Further, Bell and Fogler (1995) in reporting on the trial of the use of virtual reality in teaching chemical engineering through the program 'Vicher' identified that the use of the virtual environment gave students a sense of managing the development of their knowledge. Additionally, the virtual reality provided the ability to give tangible, corporeal substance to otherwise abstract ideas and concepts.

Wilson (1997) describes a virtual environment as "a computer-generated model where the participant can interact intuitively in real time with the environment or objects within it, and to some extent has a feeling of actually 'being there', or a feeling of presence" (p.1057-1058). This correlates with the concept expounded by Heaperman and Sudweeks (2001) and others (see Keppell, Kan, Messer \& Bione 2002; Paulsson \& Naeve, 2006; Stuckey-Mickell \& Tuckey-Danner, 2007), that a VLE is an environment which provides learners with the facilities to manage their own learning experience. Reeves, Herrington and Oliver (2002) conclude that exposure to learning environments which resemble real life will enhance student learning and it therefore follows that learning contexts and activities should simulate conditions and experiences which allow students to gain contextualised application of their knowledge and understanding.

Dalgarno, Hedberg and Harper (2002) identified eight potential contributions of virtual environments to student learning. The virtual fire scene environment provided on CD to JST415 students has the potential to contribute to learning in a number of these ways, specifically by "facilitating familiarisation with inaccessible environments", by "facilitating task mastery through practice of dangerous or expensive tasks" and by "improving transfer by situating learning in a realistic context".

\section{Project methodology}

The study was founded on Schutz's (1967) social phenomenology framework, aiming to "interpret and explain human action and thought". The overarching research questions for this project are founded on seeking an understanding of how participants view their experiences and the interpretivist approach allows the meanings and values of these experiences to be revealed through text which here is the account of meaningful experiences of the participants in the study.

As implied by this phenomenological framework, the interpretation of text is pivotal to understanding participants' experiences. Text suggests qualitative research, however, as Neumann (1994) indicates, the use of numbers, statistics and precise quantitative measurement can be a source of information which supplements and/or complements qualitative data. Further, the concept as reported by Bryman (1994) and cited by Punch (2005), "that a qualitative study can be used to help explain the factors underlying the 
broad relationships that are established through quantitative research", lays the foundation for a triangulation approach to the sources of data used in this study.

\section{The JST415 CD}

In addition to the virtual fire scene, the JST415 CD evaluated in this project contained: learning material divided into topic modules including voice over presentations; reference material in the form of both text and online hyperlinks; assessment tasks and marking criteria; mirroring that which is delivered and or available through the short course residential school and the paper based resources. In addition, instructions for accessing the virtual fire scenarios were included on the JST415 CD. The JST415 CD provided hyperlinks to additional academic resources, for example, guidelines for writing essays and reports and referencing, these were provided to the short course participants in a paper based format. Figure 1 shows a screen shot of the virtual fire scene.

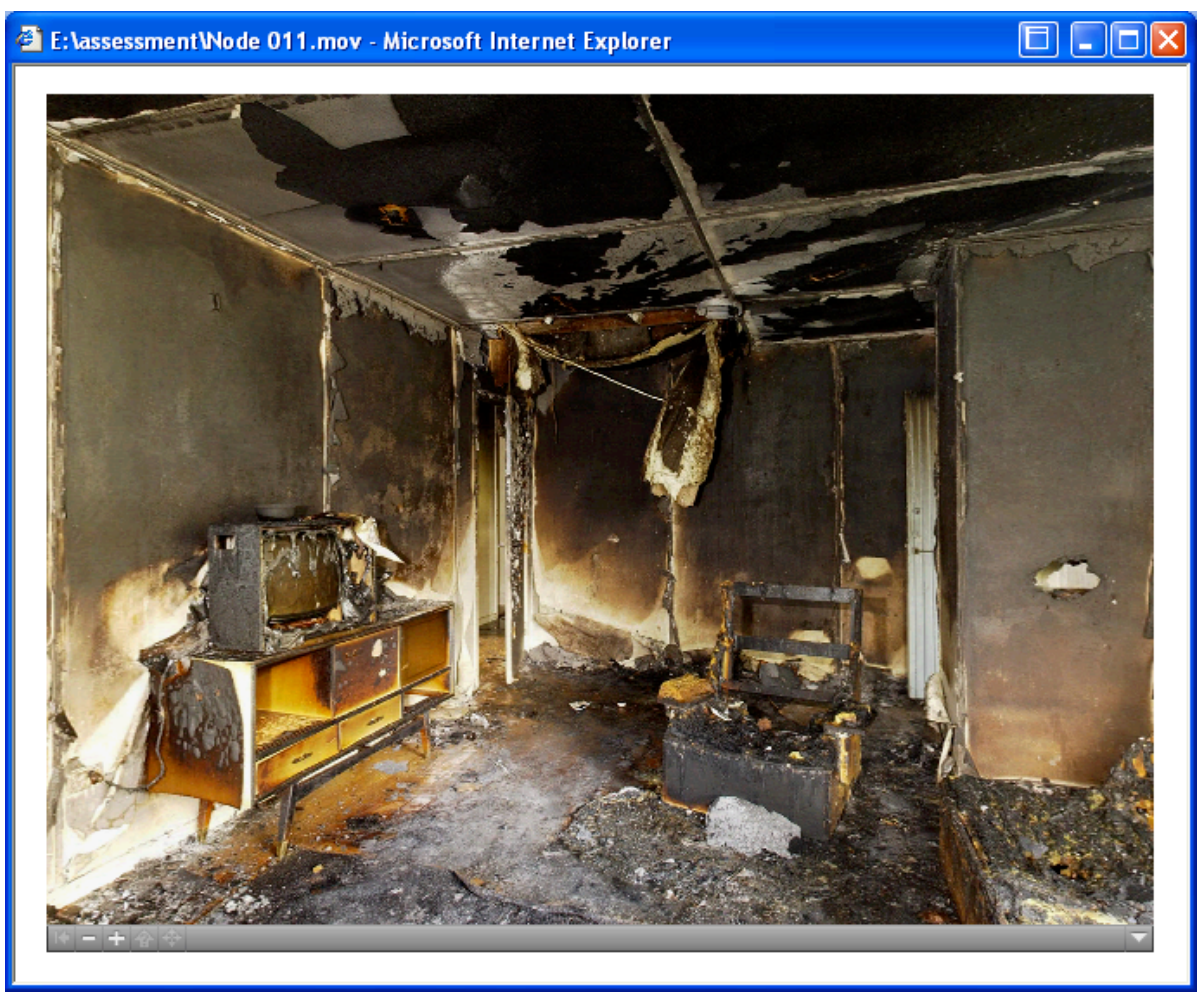

Figure 1: Screen shot from the virtual fire scene environment

\section{The learning context and research participant groups}

As indicated in the introduction, the four participant cohorts undertook their learning through separate pathways. Table 1 indicates the number of students in the four cohorts, the number of students who completed the subject JST415, and the number of students who participated in the research project through survey response and interviews. 
Table 1: Summary of student and research participant numbers

\begin{tabular}{|l|c|c|c|c|}
\hline \multirow{2}{*}{} & \multicolumn{4}{|c|}{ Group } \\
\cline { 2 - 5 } & 1 (SCRTB) & 2 (SCVA1) & 3 (SCVA2) & 4 (DEVA2) \\
\hline No .of students who commenced the course & 16 & 16 & 12 & 3 \\
\hline $\begin{array}{l}\text { No. of students who completed all course } \\
\text { assessment requirements }\end{array}$ & 14 & 8 & 4 & 1 \\
\hline $\begin{array}{l}\text { No of students who completed the evaluation of } \\
\text { the JST415 CD and submitted the research survey }\end{array}$ & 5 & 6 & 6 & 2 \\
\hline $\begin{array}{l}\text { No of students who completed all course } \\
\text { assessment requirements, evaluated the CD, } \\
\text { completed and submitted the research survey }\end{array}$ & 5 & 5 & 4 & 1 \\
\hline No of students interviewed & 1 & 1 & 2 & 1 \\
\hline
\end{tabular}

\section{Data collection}

A combination of Likert scale questions and open ended questions were included in the survey for this project. The questionnaires for all four groups were divided into three sections. The first section, Section A, contained general questions relating to the participants' level of experience with fire investigation studies and the use of online versus print based learning materials. The second section, Section $B$, related to the experience of undertaking the course assessment via the JST415 CD or real time burn. The third section, Section C, related to the evaluation of the JST415 CD in terms of accessibility, quality of materials, adequacy of the materials to prepare the student for undertaking an investigation, either real time or through the virtual environment. Additionally, participants were interviewed, providing an avenue for understanding lived experiences without the interviewer imposing any a priori categorisation. To provide triangulation of data collected in this project, participants' course assessment results were also included in the data collected.

As noted in Table 1, only 1 student from each of Group 1 and Group 2 was interviewed. This low number is attributed to the logistical difficulties experienced at the time the interviews were conducted i.e. inability to establish contact and/or time constraints due to participants working around the clock through the high fire danger season.

\section{Results}

\section{Overall value of the learning resources}

The first question addressed by this study was: Does the delivery of learning via the JST415 CD support the development of knowledge and skills for fire scene investigation? There are three separate sources of data which help to address this question. Firstly, the assessment results obtained by students in each group can be compared in order to determine whether there were measurable differences in learning for students who undertook their learning primarily face to face and those who undertook their learning primarily using the JST415 CD. Secondly, students were asked in the survey whether they thought the learning outcomes would be similar by either mode of learning delivery. And thirdly, students were asked in the interview whether they considered a student undertaking the course through distance education using the JST415 CD would be adequately prepared with the skills to investigate a fire.

Looking first at the student assessment results, as shown in Table 2, it appears that the student in group 4 who undertook their learning entirely at a distance using the JST415 
CD has performed best in the fire investigation assessment task (mean of $81 \%$ ) and has been allocated the highest competency ratings (mean of 8 out of 10), whereas students in group 1, who undertook their learning face to face and experienced a real time burn, have the lowest assessment mark (mean of 61.5\%) and the lowest competency rating (mean of 6.8). Caution is needed, however, in interpreting this finding, given that only one student studied entirely at a distance using the JST415 CD. The table also shows, however, that students who undertook their learning face to face, but with the support of the JST415 CD also performed better on the assessment task (mean of 73\%) and were allocated a higher competency rating (mean of 7.38) than students who undertook their learning face to face without the JST415 CD. Again the number of students involved (4 in each case) means that caution is needed in interpreting these results.

Table 2: Assessment results for fire investigation task

\begin{tabular}{|c|c|c|c|c|c|c|c|c|c|c|c|c|}
\hline \multirow[t]{2}{*}{ Group } & \multicolumn{3}{|c|}{$\begin{array}{l}\text { Group } 1 \\
\text { (SCRTB) }\end{array}$} & \multicolumn{3}{|c|}{$\begin{array}{l}\text { Group } 2 \\
\text { (SCVA1) }\end{array}$} & \multicolumn{3}{|c|}{$\begin{array}{l}\text { Group } 3 \\
\text { (SCVA2) }\end{array}$} & \multicolumn{3}{|c|}{$\begin{array}{c}\text { Group } 4 \\
\text { (DEVA2) }\end{array}$} \\
\hline & $\mathrm{n}$ & mean & $\mathrm{sd}$ & $\mathrm{n}$ & mean & $\mathrm{sd}$ & $\mathrm{n}$ & mean & $\mathrm{sd}$ & $\mathrm{n}$ & mean & $\mathrm{sd}$ \\
\hline Assessment 2 Mark / 100\% & 5 & 61.5 & 61 & 5 & 76.9 & 8.41 & 4 & 73 & 12.19 & 1 & 81 & 0 \\
\hline Competency Ranking / 10 & 5 & 6.8 & .4 & 5 & 7.8 & 1.17 & 4 & 7.38 & 1.39 & 1 & 8 & 0 \\
\hline
\end{tabular}

Participants in groups 2 and 3 (SCVA1 and SCVA2), who undertook a short course but were also provided with the JST415 CD to evaluate were asked to respond to the statement "I deem I would have a similar learning outcome through undertaking the short course or distance delivery of the subject via the JST415 CD". Table 3 summarises their responses. Of the respondents, only $36 \%$ thought the learning outcomes would be similar, while $54 \%$ did not, with $9 \%$ undecided.

Table 3: Responses to the statement "I deem I would have a similar learning outcome through undertaking the short course or distance delivery of the subject via the JST415 CD"

\begin{tabular}{|l|c|c|c|c|c|c|c|c|}
\hline \multicolumn{1}{|c|}{ Group } & $\mathrm{N}$ & $\begin{array}{c}\text { Very } \\
\text { strongly } \\
\text { agree }\end{array}$ & $\begin{array}{c}\text { Strongly } \\
\text { agree }\end{array}$ & Agree & $\begin{array}{c}\text { Undec- } \\
\text { ided }\end{array}$ & $\begin{array}{c}\text { Dis- } \\
\text { agree }\end{array}$ & $\begin{array}{c}\text { Strongly } \\
\text { disagree }\end{array}$ & $\begin{array}{c}\text { Very } \\
\text { strongly } \\
\text { disagree }\end{array}$ \\
\hline Group 2 (SCVA1) & 5 & 0 & 2 & 0 & 0 & 1 & 2 & 0 \\
\hline Group 3 (SCVA2) & 6 & 0 & 0 & 2 & 1 & 3 & 0 & 0 \\
\hline Overall \% & 11 & $0 \%$ & $18 \%$ & $18 \%$ & $9 \%$ & $36 \%$ & $18 \%$ & $0 \%$ \\
\hline
\end{tabular}

Through interview, participants were asked if they considered a student undertaking the course through distance education using the CD would be adequately prepared with the skills to investigate a fire. Table 4 lists extracts from interviews showing responses to this question. The responses suggest that although there would be limitations in learning solely using the CD, students would develop foundational knowledge and skills on which to build through experiential learning in the work place.

The data presented here derived from assessment results along with surveys and interviews with participants all of whom were attending real time fire investigations in their current workplace at the time of the research leads to the following finding.

Finding 1: The study of fire investigation (cause and origin determination) using the JST415 CD creates a learning environment which supports the development of foundational knowledge and skills for application by fire investigators in the workplace, although it does not provide all of the benefits of face to face learning. 
Table 4: Selected interview responses to the question "From your experience of investigating the cause and origin of fires, do you consider undertaking study by distance education utilising the JST415 CD would adequately prepare you for determining the cause and origin of fires?"

\begin{tabular}{|c|l|}
\hline Participant & \multicolumn{1}{c|}{ Comment } \\
\hline 1B & $\begin{array}{l}\text { I don't think anything prepares you for the tactile things ... in studying via the CD } \\
\text { VLE, I would have the theoretical knowledge, if I had passed the course based on } \\
\text { the CD VLE I would ask for a mentor to go with me to investigate the first couple } \\
\text { of times. }\end{array}$ \\
\hline 2B & $\begin{array}{l}\text { The learning material is very good, but it needs someone you can bounce your } \\
\text { ideas off when you first go to investigate a fire. }\end{array}$ \\
\hline 3B & $\begin{array}{l}\text { From distance learning yes ... I think that the way it is presented the distance } \\
\text { education would give them the skills. }\end{array}$ \\
\hline 3C & $\begin{array}{l}\text { I think the best preparation for investigation is to go along and investigate ... but } \\
\text { for background knowledge I do think that it would prepare you ... I didn't think } \\
\text { there was a problem with it [CD VLE] at all. }\end{array}$ \\
\hline 4B & $\begin{array}{l}\text { It has prepared me in that I have a good foundation, but it does not make me an } \\
\text { instant expert, that comes with experience of attending actual fire scenes. }\end{array}$ \\
\hline
\end{tabular}

\section{Main contribution of the VLE}

The second question addressed in this study was: What are the main aspects of a VLE that contribute to the development of knowledge and skills for fire investigation students? In the questionnaire responses and interviews, the key aspect of the VLE that emerged again and again as being of primarily importance was the ability to spend as much time as needed in the virtual fire scene and to revisit the scene as often as needed.

A number of participants made comments during the interviews about the need for the ability to, or the value of being able to, revisit the fire scene as often as required. For example, Participant 1D commented that "the ability to revisit the scene as often as required was helpful, when I did the live scene assessment it was rushed and I was rushed to make a determination". Participant $1 \mathrm{~B}$ advised that using the VLE fire scene gave them "much more time to think critically, I found with the VLE I had time to look I had time to get the big picture... I had time to think, to look, to observe and absorb". Participant 2B made a similar observation, when they did a real time fire scene investigation in the workplace, "I went backwards and forwards in the room to see what I wanted, it was similar with the VLE I went backwards and forwards without contamination of the scene". As Participant 4A observed, "[using] the CD and VLE allows you to check and recheck your work".

The issue of 'time' not only encompasses the amount of time available to view a fire scene in a learning context, it also relates to the degree of flexibility in scheduling their study. For example, Participant 3B when commenting in the survey on the advantages of the VLE, included "the ability to revisit the scene when I had time, early hours of the day when not at work, rather than the limitations of the real fire burn". Participant 2C reflected a similar observation "the ability to assess the scene at my own pace in my own time was helpful and allowed me to do a thorough assessment". Participant 4B remarked in interview "when you do a course [short course] you only see the fire scene on one day for a limited time, with the CD (VLE) you can spend as much time as you like. I know I spent a whole day looking at just one room in the virtual scenario, going backwards and forwards checking for details... when you are only at the short course real time fire scene for a limited time you need to take photos as you cannot 
completely rely on memory and then it depends if you have taken enough or the right photos, with the CD you don't have to worry about this".

The reference to an uncontaminated fire scene is a characteristic of the virtual fire scene which is problematic in the real time situation. Irrespective of the number of times the virtual fire scene is 'revisited' the data does not alter; this is not the case in the real world. Real time fire scenes are subject to the natural elements of heat, wind, cold and rain and disturbance by authorised personnel in the course of their duties and unauthorised personnel who may or may not have motive to disturb the scene. Participant 3F commented that one of the advantages of the VLE was "the ability to revisit the fire scene without any change to the scene". The comment by Participant 2B "... with the CD I went backwards and forwards without any contamination of the scene" echoed similar observations by other interviewees that the VLE provided an opportunity to return to an unaltered scene to check details and or to check the final cause and origin determination.

Participants in Group 1 (SCRTB) who undertook exploration of a real fire scene, rather than using the JST415 CD during their learning, were asked questions in the survey about whether they had sufficient time to undertake their investigation, and about whether a CD allowing them to revisit the scene would have helped. Their responses, summarised in Table 5, suggest that that there was not sufficient time to investigate the scene and that being able to revisit the scene either physically or using a virtual environment would have made the fire investigation task easier. Participants in groups 2,3 and 4 who carried out their fire investigation using a virtual burn were asked to respond to the statement "I found it assisted my study of the fire scene to have the facility to revisit the detail in the scenes as often as I needed". The mean response on this item for these three groups was 5.8, where 5 indicates agreement and 6 indicates strong agreement, with 12 of 13 respondents agreeing and the remaining respondent indicating that they were undecided.

Table 5: Group 1 participant responses to questions about time constraints in investigating a real fire

\begin{tabular}{|c|c|c|c|}
\hline Question & $\mathrm{n}$ & mean & sd \\
\hline There was sufficient time allowed to undertake the investigation of the fire scene & 4 & 2.75 & 2.09 \\
\hline $\begin{array}{l}\text { It would have enhanced the quality of my final report if I had the opportunity to } \\
\text { revisit the fire scene }\end{array}$ & 4 & 6.25 & .43 \\
\hline $\begin{array}{l}\text { On reflection it would have assisted the preparation of my fire determination if I } \\
\text { had the fire scene on CD to replay after I had left }\end{array}$ & 5 & 6.20 & .4 \\
\hline
\end{tabular}

The results presented here in relation to the value of time in fire investigation activities are encapsulated in the following finding.

Finding 2: A unique and valuable characteristic of presenting a virtual fire scene on $\mathrm{CD}$ is the unrestricted accessibility provided to the scene for investigation studies.

\section{Potential limitations of the VLE}

The third question addressed by the study was: What are the limitations of the use of a $V L E$ when compared with a similar face to face experience and do these impact on learning? 
Three aspects of a virtual environment could potentially limit the learner's ability to effectively use and learn within the environment. These are the limited field of view within the environment, the visual fidelity provided by the environment, and the mechanism for navigating through or looking around the environment. The degree to which each of these impacted on learning is discussed in the following sections.

Field of view and visual fidelity

Table 6 presents the results of survey questions about characteristics of the VLE that may have impacted on its effectiveness. The responses to the first question in the table suggest that some participants found that the field of view was not sufficient. This is a common limitation of virtual environments and is difficult to address without the use of immersive virtual environment equipment such as CAVEs, which use projected displays that surround the viewer (McLellan, 1996). Importantly, however, responses to the second and third questions suggest that most participants were nevertheless able to view the necessary detail to carry out the investigation activity. Visual fidelity is a common limitation of $3 \mathrm{D}$ virtual environments, which require rendering of the scene every time the participant moves. Photorealistic environments typically provide greater visual realism than 3D virtual environments, although (as discussed below) they provide limitations in the flexibility of movement within the environment.

These responses relating to the field of view and visual detail provided by the VLE lead to the following finding.

Finding 3: The virtual fire scene provided on $\mathrm{CD}$ provided sufficient field of view and sufficient visual fidelity to allow most students to undertake a realistic fire investigation activity.

Table 6: Responses to questions about specific aspects of the virtual fire scene

\begin{tabular}{|c|c|c|c|c|c|c|c|c|c|c|c|c|}
\hline \multirow[t]{2}{*}{ Question } & \multicolumn{3}{|c|}{$\begin{array}{l}\text { Group } 1 \\
\text { (SCRTB) }\end{array}$} & \multicolumn{3}{|c|}{$\begin{array}{l}\text { Group } 2 \\
\text { (SCVA1) }\end{array}$} & \multicolumn{3}{|c|}{$\begin{array}{l}\text { Group } 3 \\
\text { (SCVA2) } \\
\end{array}$} & \multicolumn{3}{|c|}{$\begin{array}{l}\text { Group } 4 \\
\text { (DEVA2) }\end{array}$} \\
\hline & $\mathrm{n}$ & mean & $\mathrm{sd}$ & $\mathrm{n}$ & mean & $\mathrm{sd}$ & $\mathrm{n}$ & mean & $\mathrm{sd}$ & $\mathrm{n}$ & mean & $\mathrm{sd}$ \\
\hline $\begin{array}{l}\text { I found the 'field of view' of } \\
\text { the virtual fire scene was } \\
\text { sufficient }\end{array}$ & 0 & 0 & 0 & 5 & 5.8 & .98 & 6 & 4.83 & 1.34 & 2 & 3 & 1 \\
\hline $\begin{array}{l}\text { I was able to view all the } \\
\text { necessary detail required to } \\
\text { determine the cause and origin } \\
\text { of the fire in the virtual } \\
\text { environment }\end{array}$ & 5 & 5.2 & .75 & 5 & 5.2 & 1.33 & 6 & 5.17 & 1.25 & 2 & 4 & 1 \\
\hline $\begin{array}{l}\text { I found the virtual environ- } \\
\text { ment provided me with } \\
\text { sufficient detail to complete } \\
\text { my assessment of the fire }\end{array}$ & 5 & 5.2 & .75 & 5 & 5.6 & 1.08 & 5 & 5 & 1.1 & 2 & 4 & 1 \\
\hline $\begin{array}{l}\text { I found it assisted my study of } \\
\text { the virtual fire scene to be able } \\
\text { to navigate around the room, } \\
\text { to the floor and ceiling and to } \\
\text { enlarge hot spots }\end{array}$ & 5 & 6.2 & .98 & 5 & 6.2 & .75 & 6 & 5.5 & .76 & 2 & 5 & 0 \\
\hline
\end{tabular}

\section{Manoeuvrability}

The remaining possible limitation of a virtual environment for fire investigation is the facility provided to navigate within the scene being assessed. 3D virtual environments 
can allow smooth movement through an environment in any direction, with the view dynamically changed to reflect the current view position and direction. Photorealistic virtual environments, on the other hand, restrict the view positions to a set of predetermined positions from which the photos used to create the environment were taken. This restricts navigation to zooming and panning from one position and jumping to a new position.

Interestingly, this limitation was only identified by one of the participants, Participant $3 \mathrm{E}$, who commented that "I was unable to go to places I wanted to go and zoom in, such as the area between the bed and bedside table, there was no external view". In contrast to these comments, Participant $3 \mathrm{C}$ was complementary in regards to the detail and facility available, and when asked what was it specifically that they found useful the following comments were proffered: "I guess it was like you were standing there, the ability to do a $360^{\circ}$ in the room, three different positions, to get a picture of it from all different angles, also it did go up to the ceiling, and you can tell a lot from your ceilings in terms of where your fire has been". Other students also tended to comment positively about the navigation facilities provided. For example, Participant 1A commented that revisiting the fire scene on the virtual video is great for going over scenes and it was helpful to move the picture for different angles. Participant $1 \mathrm{~B}$ indicated "I liked the ability to be able to move through the scenario from least damaged to most damaged, to zoom in on various bits of evidence... it was amazing". Participant 1D and 1E made similar observations "...by moving around the room assisted especially when checking possible origins..." and "I found the navigation and manoeuvrability around the room helpful."

The responses to the question about manoeuvrability in the survey, as shown in Table 6, which asked whether the navigation capabilities provided assisted with the task, also suggests that participants found the capabilities of the tools provided for navigation quite adequate. The responses to survey questions and the comments in the interviews about the navigation capabilities provided by the VLE lead to the following finding:

Finding 4: The navigation capabilities provided by the virtual fire scene provided on $\mathrm{CD}$ are sufficient to allow completion of the fire investigation activities.

\section{Discussion and conclusion}

This has paper discussed the impact on learning outcomes of the utilisation of a virtual reality scenario for teaching fire investigators foundational skills for their workplace practice. Further, this paper has identified characteristics of the virtual environment which in this study contributed to students' uptake of knowledge in the JST415 fire investigation subject. The findings proffered in this paper attempt to build on the developing body of knowledge seeking to understand how advances in technology may be harnessed to deliver education for professional practice. Whilst there remains much to be learnt in this arena, the results from this study support progressing research efforts to embrace the use of virtual environments to allow for students to undertake simulated practical tasks in situations where the real tasks cannot conveniently or affordably be undertaken. 


\section{Acknowledgements}

The authors wish to acknowledge the assistance of the NSW Police Forensic Unit for their contribution in providing the ISRAPS footage. The authors also wish to acknowledge the assistance of Mr Ross Brogan and Mr Glen Jacobsen, Adjunct Lecturers and Subject Coordinators for JST415 Fire Investigation Cause and Origin Determination for the Australian Graduate School of Policing, Charles Sturt University.

\section{References}

Bell, J. T. \& Fogler, S. H. (1995). The investigation and application of virtual reality as an educational tool. Proceedings of the American Society for Engineering Education 1995 Annual Conference, Session No 2413. Anaheim, CA.

Bell, J. T. \& Fogler, S. H. (1996). Vicher: A virtual reality based educational module for chemical reaction engineering. Computer Applications in Engineering Education, 4(4).

Bricken, W. (1990). Learning in virtual reality. (Tech.Memo.M-90-5). Seattle, WA: Human Interface Technology Laboratory, University of Washington.

Bryman, A. \& Burgess, R. (Eds) (1994). Analyzing qualitative data. Routledge.

Byrne, C. M. (1996). The use of virtual reality as an educational tool. (Doctoral dissertation for University of Washington). [viewed 10 Jan 2008, verified 13 Feb 2009] http: / / www.hitl.washington.edu/ publications / dissertations / Byrne/

Chen, E. C. (1995). QuickTime VR - An image based approach to virtual environment navigation. Proceedings of the 22nd annual conference on computer graphics and interactive techniques (pp. 29-38). Los Angeles, California, ACM Press.

Dalgarno, B., Hedberg, J. \& Harper, B. (2002). The contribution of 3D environments to conceptual understanding. In Winds of change in the sea of learning: Charting the course of digital education. Proceedings ascilite Auckland 2002.

http:/ / www.ascilite.org.au/conferences/auckland02/ proceedings/ papers/051.pdf

Dillenbourg, P., Schneider, D. K. \& Synteta, P. (2002). Virtual learning environments. In A. Dimitracopoulou (Ed), Proceedings of the 3rd Hellenic Conference on Information $\mathcal{E}$ Communication Technologies in Education (pp. 3-18). Kastaniotis Editions, Greece.

Heaperman, S. \& Sudweeks, F. (2001). Achieving self-efficacy in the virtual learning environment. In W. Shilton \& R. Jeffery (Eds), Crossing borders: New frontiers for educational research. Australian Association for Research in Education Conference, AARE Inc, Coldstream, VIC. http:/ / www.aare.edu.au/01pap/hea01715.htm

Jonassen, D. (1995). Computers as cognitive tools: Learning with technology, not from technology. Journal of Computing in Higher Education, 6(2), 40-73.

Jonassen, D. H., Howland, J., Moore, J. L. \& Marra, R. M. (2003). Learning to solve problems with technology: A constructivist perspective. (2nd ed.). Ohio: Merrill Prentice Hall.

Keppell, M., Kan, K., Messer, L. \& Bione, H. (2002). Authentic learning interactions: Myth or reality? In Winds of change in the sea of learning: Charting the course of digital education. Proceedings ascilite Auckland 2002.

http:/ / ascilite.org.au/conferences / auckland02/ proceedings/ papers / 167.pdf

McLellan, H. (1996). Virtual realities. In D. H. Jonassen (Ed), Handbook of research for educational communications and technology (pp. 457-490). New York: Simon and Schuster. 
Paulsson, F. \& Naeve, A. (2006). Virtual workshop environment (VWE): A taxonomy and service oriented architecture (SOA) Framework for Modularized Virtual Learning Environments (VLE) - applying the learning object concept to the VLE. International Journal of E-Learning. $5(1)$.

Neuman, W. L. (1994). Social research methods. 2nd ed. London: Allyn and Bacon.

Punch, L. (2005). Introduction to social research quantitative and qualitative approaches. 2nd edn. London: Sage Publications.

Reeves, T. C., Herrington, J. \& Oliver, R. (2002). Authentic activities and online learning. Proceedings HERDSA 2002. pp.562-567. http:/ / www.herdsa.org.au/wpcontent/uploads/conference/2002/ papers/Reeves.pdf

Schutz, A. (1967). The phenemology of the social world. Illinois. Northern University Press.

Stuckey-Mickell, T. A. \& Tuckey-Danner, B. D. (2007). Virtual labs in the online biology course: Student perceptions of effectiveness and usability. Journal of Online Learning and Teaching, $3(2)$.

Wann, J. \& Mon-Williams, M. (1996). What does virtual reality NEED? Human factors issues in the design of three-dimensional computer environments. International Journal of HumanComputer Studies, 44, 829-847.

Wilson, J. R. (1997). Virtual environments and ergonomics: Needs and opportunities. Ergonomics, 40(10).

This article received an Outstanding Paper Award at ascilite Melbourne 2008 Conference, gaining the additional recognition of republication with minor corrections in AJET. The reference for the Conference version is:

Davies, A. \& Dalgarno, B. (2008). Learning fire investigation the clean way: The virtual experience. In Hello! Where are you in the landscape of educational technology? Proceedings ascilite Melbourne 2008.

http:/ / www.ascilite.org.au/ conferences / melbourne08/procs / davies.pdf

Amanda Davies MEd, BA, Grad Dip Ad., Grad Cert ULET, School of Policing Studies, Charles Sturt University. Email: adavies@csu.edu.au

Dr Barney Dalgarno, Associate Professor, Faculty of Education, and Research Fellow, Centre for Research in Complex Systems, Charles Sturt University.

Email:bdalgarno@csu.edu.au 